\title{
Malignant and pre-malignant oesophageal pathology in a South African teaching hospital
}

\author{
E Loots,,${ }^{1,2}$ P K Ramdial, ${ }^{3}$ B Sartorius, ${ }^{4}$ C M Mulder, ${ }^{6}$ D L Clarke ${ }^{2,5,7}$ \\ ${ }^{1}$ Department of Surgery, Inkosi Albert Luthuli Central Hospital, Durban, South Africa \\ ${ }^{2}$ Department Of Surgery, University of KwaZulu-Natal, Durban, South Africa \\ ${ }^{3}$ Department Of Anatomical Pathology, University of KwaZulu-Natal, Durban, South Africa \\ ${ }^{4}$ Discipline of Public Health Medicine, School of Nursing and Public Health, University of KwaZulu-Natal, Durban, \\ South Africa \\ ${ }^{5}$ Department Of Surgery, Grey’s Hospital, Pietermaritzburg, South Africa \\ ${ }^{6}$ Department of Hepatogastroenterology, VU University Medical Centre Amsterdam, the Netherlands \\ ${ }^{7}$ Department Of Surgery, School of Clinical Medicine, University of the Witwatersrand, South Africa
}

Corresponding author: E.Loots (emilloots@hotmail.com)

\begin{abstract}
Background: South Africa (SA) has one of the highest global incidences of squamous cell carcinoma of the oesophagus (SCC). A decreasing incidence of oesophageal SCC in SA has been suggested. The study aimed to assess whether the incidence of these malignant histopathological subtypes has changed in this setting.

Methods: A retrospective review of histopathological reports on pre-malignant and malignant oesophageal lesions over three time periods (TP), namely: 2003-4 (TP1), 2008-9 (TP2) and 2013-14 (TP3) was carried out at Inkosi Albert Luthuli Central Hospital, Durban, South Africa.

Results: A total of 1341 specimen reports were retrieved. TP1-3 consisted of $514(39.3 \%), 320(24.5 \%)$ and $474(36.2 \%)$ patients respectively. Six hundred and forty-nine patients were male (48.3\%), 642 were female $(47.8 \%)$ and 50 were not specified. i.e. a sex ratio of 1.01:1. The mean age was $60.8( \pm 11.8)$. There were 1197 Black patients $(91.5 \%), 66$ Asian $(5.1 \%), 25$ White $(1.9 \%), 9$ mixed ancestry $(0.7 \%)$, and 11 of unknown race $(0.8 \%)$. SCC was the most common cancer 1098 $(89.1 \%)$ followed by adenocarcinoma (AC) 69 (5.6\%). The ratio of SCC to AC remained fairly consistent over the total time period. Seventy-four oesophageal resections were performed with a yearly average resection rate of only $5.6 \%$.

Conclusions: SCC is still the most prevalent oesophageal cancer (OC) without an increase in the ratio of AC to SCC. The diagnosis of squamous cell dysplasia is concordant with previously cited rates. Barrett's oesophagitis remains uncommon. Resection rates for OC are low but similar to other South African referring centers.

Keywords: Oesophageal cancer, squamous cell cancer, South Africa, pre-malignant oesophageal lesions, oesophageal resection, adenocarcinoma

Abbreviations: SA - South Africa; SCC - Oesophageal squamous cell cancer; OC - Oesophageal cancer; BO - Barrett's oesophagitis; TP1 - Time period 1; TP2 - Time period 2; TP3 - Time period 3; IALCH - Inkosi Albert Luthuli Central Hospital; KZN - KwaZulu-Natal; AJCC - American Joint Committee on Cancer ; UICC - International Union Against Cancer ; TNM - Tumor Node Metastasis
\end{abstract}

S Afr J Surg 2018;56(1)

http://dx.doi.org/10.17159/2078-5151/2018/v56n1a2076

\section{Background}

Oesophageal cancer is the $4^{\text {th }}$ most common cause of cancerrelated fatality amongst males in the developing countries, and the $8^{\text {th }}$ most common cause amongst males in developed countries. ${ }^{1}$ Although the incidence is twenty-fold higher in the developing world compared to developed countries, the spectrum of disease is different with adenocarcinoma being the most common form in the developed world and squamous carcinoma being the most common form in the developing world. ${ }^{1}$ Barrett's oesophagitis (BO) with dysplasia is a precursor lesion for the development of adenocarcinoma of the oesophagus (AC) and many developed countries have dedicated guidelines for this condition. ${ }^{2}$ In contrast, the Eastern Cape Province (former Transkei) of SA has one of the highest incidences of oesophageal squamous cell carcinoma (OSCC) in the world. This remains true despite recent 
evidence to suggest that there may be a significant decrease in the incidence in the Eastern Cape Province. ${ }^{3,4}$ Squamous cell dysplasia is a precursor lesion in the development of OSCC. ${ }^{5}$ Screening for OSCC in SA is not developed and not applied in clinical practice in private and public hospitals. ${ }^{6}$

Surgery, in combination with chemotherapy or radiotherapy, offers the only chance of cure for OC. Resection rates of up to $26.4 \%$ have been reported in the developed world. ${ }^{7}$ However, in South Africa, a recent report from Cape Town showed a much lower resection rate of $6.1 \%{ }^{8}$ The goal of surgery is an $\mathrm{R} 0$ resection containing $\geq 15$ lymph nodes, which will allow adequate staging of lymph node status according to the National Comprehensive Cancer Network (NCCN) guidelines. ${ }^{9}$ There is lack of data from SA on the South African experience of oesophageal resection rates for malignancy and on the adequacy and quality of such resections. No data on morbidity and or mortality is available.

This study was a retrospective review of histopathology reports from three different time periods ranging over 12 years and aimed to assess whether there was a change in the hospital incidence or histopathological subtypes of OC in KwaZuluNatal (KZN), SA. A further aim was to assess the resection rates and adequacy of resection for OC in KZN.

\section{Methods}

A retrospective histopathology report review was carried out at Inkosi Albert Luthuli Central Hospital (IALCH), Durban, South Africa. The laboratory receives specimens from the Ethekwini region and from the North and South Coasts of KZN. The University of KZN Biomedical Research Ethics Committee (BREC) supplied class approval for creation of a comprehensive database on oesophageal cancer. The three comparative time periods selected were as follows: 2003-4 (TP1), 2008-9 (TP2) and 2013-14 (TP3). Oesophageal biopsies were accessed from the department of Anatomical Pathology database using SNOMED word search for "oesophagus" and "oesophageal" specimens. Histopathological reports based on either punch biopsy or oesophageal resections were analyzed. The sixth edition of the American Joint Committee on Cancer (AJCC)/International Union Against Cancer (UICC) tumor-node-metastasis (TNM) classification was used for TP1/TP2 and the seventh edition was used for TP $3 .{ }^{10-12}$ The difference between the two classifications was that "squamous cell carcinoma in situ" was used in the $6^{\text {th }}$ edition but the $7^{\text {th }}$ edition classified carcinoma in situ as "high-grade squamous cell dysplasia". In this paper we included "carcinoma in situ" in the category of "high-grade squamous cell dysplasia" to accommodate this difference and this was applied for the three TPs. Demographic data, the site of specimen biopsy and the type of specimen collection were also documented. Further information on resection specimens was documented including the type of tumour and grading, site of the tumour, resection margins and tumour staging according to the histopathologist's final report. The site of tumour was based on the clinical history on the histopathology request form or reported level from the incisor teeth. The endoscopic classification of the level of OC was the measurement from the incisor teeth to the level of the lesion, with proximal being $15-18 \mathrm{~cm}$, middle $19-31 \mathrm{~cm}$ and distal from $32 \mathrm{~cm}$ up to the level of oesophago-gastric junction. ${ }^{11}$

\section{Statistical analysis}

Data was processed and analyzed using Stata 13.0 (StataCorp. 2013. Stata Statistical Software: Release 13. College Station, TX: StataCorp LP.). Difference in continuous normally distributed variables by dichotomous group was analyzed using the Student's T-test. Comparison of means across $\geq 3$ groups was analyzed using one way analysis of variance (ANOVA). Associations between categorical variables were assessed using the Pearson Chi-squared $\left(\chi^{2}\right)$ test. If an expected cell count was less than 5 observations then the Fishers exact test was used instead. Relative changes (odds ratios) in cancer type by period were estimated using logistic regression. A p-value of $<0.05$ was used to define statistical significance.

\section{Results}

A total of 1341 specimens were collected, and the breakdown per time period was as follows; TP1 521 (38.9\%), TP2 346 (25.8\%) and TP3 474 (35.3\%). There were 649 (48.3\%) males and 642 females $(47.8 \%)$ with a ratio of $1.01: 1$. Fifty subjects $(3.7 \%)$ had no sex status specified. The mean age (among the 1209 with specified age) was 60.8 years ( $\mathrm{SD} \pm 11.8)$. The ethnic distribution was as follows: 1197 (91.5\%) Black, 66 (5.1\%) Asian, 25 (1.9\%) White, 9 (0.7\%) mixed ancestry and $44(3.2 \%)$ unknown. The tumour type and differentiation are displayed in Table 1. The overall SCC to AC ratio was 15.9:1. There was an increase in the ratio in favor of SCC relative to AC from TP1 to TP3 (OR 1.29), though this was not statistically significant $(\mathrm{p}$-value $=0.436)$. In TP2 there was a significant increase in AC relative SCC over this period (OR $0.52 ; \mathrm{p}$-value $=0.024)$.

A total of $74(5.6 \%)$ patients underwent oesophageal resections over the study period and this is summarized in Table 2. There was a marginally significant decrease in the number of resections over the time periods from $33(6 \%)$ in TP1 to $23(7 \%)$ TP2 and 19 (4\%) TP3 (p-value $=0.099)$. The tumour type resected was consistent with SCC predominating (84-87\%). The number of resections of the upper and middle oesophagus decreased but this was not statistically significant ( $p$-value $=0.275)$. The number of resections performed also decreased from $17(51 \%)$ in TP1, $10(43 \%)$ in TP2 and $6(2 \%)$ in TP3 ( $p$-value $=0.007)$. A significantly lower rate of positive margins was observed from TP1 to TP3 $(p$-value $=0.001)$ along with an increase in the average number of lymph nodes resected; however this did not reach significance.

\section{Discussion}

Squamous Cell Carcinoma (SCC) remained the most common histopathological cancer subtype (84.2\%) without any change 
Table 1: Tumour type and differentiation by time period

\begin{tabular}{|c|c|c|c|c|}
\hline Type of tumour & TP1: 2003-2004 & TP2: 2008-2009 & TP3: 2013-2014 & Overall \\
\hline Malignant & $501(9.6)$ & $290(83.8)$ & $440(92.8)$ & 1231 (91.8) \\
\hline $\mathrm{SCC}$ & $449(86.1)$ & $254(73.4)$ & $395(83.3)$ & $1098(81.2)$ \\
\hline G1 Well diff & $3(0.6)$ & $0(0)$ & $0(0)$ & $3(0.2)$ \\
\hline G2 Mod diff & $360(69)$ & $230(66.5)$ & $304(64.1)$ & $894(66.7)$ \\
\hline G3 Poor diff & $30(5.7)$ & $8(2.3)$ & $9(1.9)$ & $47(3.5)$ \\
\hline $\mathrm{GX}=\mathrm{G} 1$ & $56(10.7)$ & $16(4.6)$ & $82(17.3)$ & $154(11.5)$ \\
\hline $\mathrm{AC}$ & $25(4.8)$ & $27(7.8)$ & $17(3.6)$ & $69(5.1)$ \\
\hline Adenosquamous & $3(0.6)$ & $0(0)$ & $1(0.2)$ & $4(0.3)$ \\
\hline NET & $3(0.6)$ & $1(0.3)$ & $7(1.5)$ & $10(0.7)$ \\
\hline Kaposi Sarcoma & $1(0.2)$ & $0(0)$ & $0(0)$ & $1(0.1)$ \\
\hline GIST & $1(0.2)$ & $0(0)$ & $0(0)$ & $1(0.1)$ \\
\hline Other & $19(3.6)$ & $8(2.3)$ & $20(4.2)$ & $16(1.2)$ \\
\hline Pre-malignant & $20(3.8)$ & $56(16.2)$ & $34(7.2)$ & $110(8.2)$ \\
\hline SC dysplasia & $19(3.6)$ & $55(15.9)$ & $31(6.5)$ & $105(7.8)$ \\
\hline $\mathrm{BO}$ & $0(0)$ & $1(0.3)$ & $3(0.6)$ & $4(0.3)$ \\
\hline Unknown & $1(0.2)$ & $0(0)$ & $0(0)$ & $1(0.1)$ \\
\hline Total & $521(38.9)$ & $346(25.8)$ & $474(35.3)$ & 1341 \\
\hline
\end{tabular}

Table 2: Characteristics of oesophageal resections by time period

\begin{tabular}{|c|c|c|c|c|}
\hline Characteristic & TP1 & TP2 & TP3 & p-value \\
\hline & 521 & 346 & 474 & \\
\hline Number of resections (\%) & $33(6)$ & $23(7)$ & $19(4)$ & 0,172 \\
\hline \multicolumn{5}{|l|}{ Position } \\
\hline Distal & $18(54)$ & $18(78)$ & $14(74)$ & 0,168 \\
\hline Middle & $14(42)$ & $5(28)$ & $5(26)$ & \\
\hline Upper & $1(3)$ & $0(0)$ & $0(0)$ & \\
\hline \multicolumn{5}{|l|}{ Type of tumour: $n(\%)$} \\
\hline $\mathrm{AC}$ & $4(12)$ & $2(9)$ & $2(11)$ & 0,38 \\
\hline SCC & $29(87)$ & $20(87)$ & $16(84)$ & \\
\hline $\mathrm{SCC}$ is & $0(0)$ & $1(4)$ & $1(5)$ & \\
\hline \multicolumn{5}{|l|}{ T Staging } \\
\hline $\mathrm{T} 4$ & $17(51)$ & $10(43)$ & $6(32)$ & 0,006 \\
\hline T3 & $7(21)$ & $8(35)$ & $7(37)$ & \\
\hline $\mathrm{T} 2$ & $0(0)$ & $3(13)$ & $5(26)$ & \\
\hline $\mathrm{T} 1$ & $0(0)$ & $0(0)$ & $0(0)$ & \\
\hline Tis & $0(0)$ & $1(4)$ & $0(0)$ & \\
\hline $\mathrm{Tx}$ & $9(27)$ & $1(4)$ & $1(5)$ & \\
\hline \multicolumn{5}{|l|}{ Resection } \\
\hline Positive margins: $\mathrm{n}(\%)$ & $59(15)$ & $2(9)$ & $1(5)$ & $<0.001$ \\
\hline Lymph nodes per resection specimen: mean (SD) & $4.8(5.4)$ & $5.4(5.4)$ & $5.7(7.7)$ & $\mathbf{0 , 8 6 2}$ \\
\hline
\end{tabular}


in the overall SCC to AC ratio. Similar results have been reported in Cape Town, SA, which is in keeping with trends in other developing countries.

Gould et al. from Johannesburg in the Gauteng Province reported a decrease in the number of OC cases diagnosed, however this trend has not been shown in our study. ${ }^{3}$

The results showed that the ratio of SCC to AC has remained constant. There was a decrease in the number of OC cases and an increase of AC diagnosed in TP2, but this did not reach statistical significance over the three time periods. A plausible explanation may be the endoscopic equipment failures that periodically disrupt endoscopic services at both regional and tertiary hospitals, resulting in false and apparent decreases in incidence. ${ }^{13}$

Premalignant conditions (dysplasia and carcinoma in situ) for SCC represented 7.8\% and Barret's Oesophagitis (BO) represented $0.3 \%$ of cases. High-grade squamous cell dysplasia has been shown to be a significant risk factor in the development of SCC. ${ }^{5}$ The incidence of BO is not known amongst Black Africans in SA.

The oesophageal resection rate of $5.6 \%$ was in keeping with the findings published from Cape Town. ${ }^{8}$ Resections were performed for lower T stages in TP2 and TP3. Unfortunately, the number of resection specimens with positive margins was higher than expected. There was an unexpected low yield in the number of lymph nodes harvested considering the NCCN guidelines. ${ }^{9}$ The reason for this is unclear and whether it reflects inadequate surgical technique, histopathological under-sampling or underreporting remains to be elucidated. Survival outcomes data were unavailable.

OSCC remains the most prevalent cancer in SA and other developing countries as opposed to the developed world where $\mathrm{AC}$ is increasing in incidence. ${ }^{14}$ Our cohort has a low resection rate in keeping with a poorly resourced environment, which limits access to multi-modality treatment.

Low resection rates for $\mathrm{OC}$ unfortunately remain consistent. Any attempts to improve this will depend upon the development of dedicated multi-disciplinary teams in centralized centers. Standardization of surgical technique and histopathological reporting should be implemented to improve both the quality of resections and surgical outcomes. The study limitations include that it is retrospective and that actual operative patient outcomes are not known.

\section{Conclusions}

The study showed that SCC is still the most prevalent OC in our setting without any change in the subtype. Surgical margins and lymphadenectomy, although they showed improvement over the three TPs, were sub-optimal. The resection rates for $\mathrm{OC}$ are lower than those abroad, yet comparable to other SA centers.

\section{REFERENCES}

1. Torre LA, Bray F, Siegel RL, Ferlay J, Lortet-Tieulent J, Jemal A. Global cancer statistics, 2012. CA Cancer J Clin. 4 Feb 2015. PubMed PMID: 25651787. Epub 2015/02/06. Eng.
2. Fitzgerald RC, di Pietro M, Ragunath K, Ang Y, Kang JY, Watson P, et al. British Society of Gastroenterology guidelines on the diagnosis and management of Barrett's oesophagus. Gut. Jan 2014;63(1):7-42. PubMed PMID: 24165758. Epub 2013/10/30. eng.

3. Gould. A, Morgan. H, Motha. N, Makda. M, Domingo. A, Tiedt. $\mathrm{S}$, et al. Comparison of the incidence of oesophageal cancer in two 6-year periods from selected hospitals in and around Gauteng Province, South Africa. S Afr J Surg. 2015;53(2):55-8.

4. Somdyala NI, Parkin DM, Sithole N, Bradshaw D. Trends in cancer incidence in rural Eastern Cape Province; South Africa, 1998-2012. Int J Cancer. 1 Mar 2015;136(5):E470-4. PubMed PMID: 25236502. Epub 2014/09/23. Eng.

5. Wang GQ, Abnet CC, Shen Q, Lewin KJ, Sun XD, Roth MJ, et al. Histological precursors of oesophageal squamous cell carcinoma: results from a 13 year prospective follow up study in a high risk population. Gut. Feb 2005;54(2):187-92. PubMed PMID: 15647178. Pubmed Central PMCID: PMC1774842. Epub 2005/01/14. eng.

6. Lazarus C, Jaskiewicz K, Sumeruk RA, Nainkin J. Brush cytology technique in the detection of oesophageal carcinoma in the asymptomatic, high risk subject; a pilot survey. Cytopathology. 1992;3(5):291-6. PubMed PMID: 1288654. Epub 1992/01/01. eng.

7. Stavrou EP, Ward R, Pearson SA. Oesophagectomy rates and post-resection outcomes in patients with cancer of the oesophagus and gastro-oesophageal junction: a populationbased study using linked health administrative linked data. BMC Health Serv Res. 2012;12:384. PubMed PMID: 23136982. Pubmed Central PMCID: PMC3556094. Epub 2012/11/10. eng.

8. Dandara C, Robertson B, Dzobo K, Moodley L, Parker MI. Patient and tumour characteristics as prognostic markers for oesophageal cancer: a retrospective analysis of a cohort of patients at Groote Schuur Hospital. Eur J Cardiothorac Surg. 12 Apr 2015. PubMed PMID: 25870217. Eng.

9. Ajani JA, Barthel JS, Bekaii-Saab T, Bentrem DJ, D'Amico TA, Fuchs CS, et al. Esophageal cancer. J Natl Compr Canc Netw. Oct 2008;6(9):818-49. PubMed PMID: 18926093. Epub 2008/10/18. eng.

10. Rice TW. Esophageal Cancer Staging. Korean J Thorac Cardiovasc Surg. Jun 2015;48(3):157-63. PubMed PMID: 26078921. Pubmed Central PMCID: PMC4463223. Epub 2015/06/17. eng.

11. American Joint Committee on Cancer; American Cancer Society; American College of Surgeons. AJCC cancer staging manual. 7th ed. New York: Springer; 2010.

12. American Joint Committee on Cancer; American Cancer Society; American College of Surgeons. AJCC cancer staging manual. 6th ed. New York: Springer; 2002.

13. Thomson SR. SAGES report on academic gastro-intestinal unit survey. S Afr Med J. Nov 2004;94(11):894-5. PubMed PMID: 15587448. Epub 2004/12/14. eng.

14. Hofstetter W, Swisher SG, Correa AM, Hess K, Putnam JB, Jr., Ajani JA, et al. Treatment outcomes of resected esophageal cancer. Ann Surg. Sep 2002;236(3):376-84; discussion 845. PubMed PMID: 12192324. Pubmed Central PMCID: PMC1422591. Epub 2002/08/23. eng. 